\title{
A NEURO-FUZZY CONTROL OF A DC SHUNT MOTOR
}

\author{
Ahmad N. Al-Husban \\ Al-Balqa Applied University, College for Engineering Technology, \\ Amman, Jordan
}

(Received February 12, 2006 Accepted March 26, 2006)

\begin{abstract}
This paper presents a novel methodology for designing a neuro-fuzzy control for controlling systems with nonlinearities of known structures and parameters. Due to the different nonlinearities inherent in the system dynamics, we propose a neural-fuzzy control that processes both numerical and linguistic information. The proposed control has some characteristics and advantages, the inputs and outputs are fuzzy numbers or numerical numbers, the weights of the proposed neuro-fuzzy control are fuzzy weights owing to the representation forms of the alpha-level sets.

Different tests are performed to study the effects of different alpha-cut techniques on the closed loop system performance, the first test addresses the effect of alpha-cut techniques, the second test is related to the effect of number of labels and finally the effect of defuzzification techniques.

This approach is able to process and learn numerical information as well as linguistic information. It can be used as an adaptive fuzzy controller. As a model example of nonlinear system, the DC shunt motor is considered due to its importance in electric drive. Computer simulations are included to help in conducting the study.
\end{abstract}

KEYWORDS: Neuro-Fuzzy Control, Nonlinearities, Fuzzy Weights, Alpha-Level, Closed Loop Performance, DC Shunt Motor.

\section{INTRODUCTION}

Fuzzy systems and neural networks are both soft computing approaches for modeling expert behavior, the term soft computing was coined by Lotfi A. Zadeh $[1,2]$. In traditional hard computing, the prime desiderates are precision and certainty. By contrast, the point of departure in soft computing is that precision and certainty carry cost and that computation, reasoning, and decision making should exploit.

The goal is to mimic the actions of an expert who solves complex problems, this means that we do not want to model the problem itself by creating a mathematical model that follows some physical or logical representations; rather, we examine how an expert deals with the problem, and try to make use of the observation. Neural networks and fuzzy systems seem to be totally different areas with merely marginal connections to each other [3-10]. 
Recently, neural network models have been introduced that are in fact closely related to fuzzy systems. We will show that combinations of neural networks with fuzzy systems, so-called neural-fuzzy or neuro-fuzzy systems. By a neuro-fuzzy system one understands a system which involves in some way both fuzzy systems and neural networks, or features of both combined in a single system. The most important reason for combining fuzzy systems with neural networks is their learning capability, such a combination should be able to learn linguistic rules and/or membership functions, or to optimize existing ones, learning means creating a rule-base or membership functions. Therefore, combing neural networks with fuzzy set could combine the advantage of symbolic and numerical processing. Neural networks and fuzzy systems estimate functions from sample data, they do not require a mathematical model, so they are model-free estimators [3-10]. While the learning capability is an advantage from the view point of a fuzzy system, from the view point of a neural network there are additional advantages to a combined system. Because a neuro-fuzzy system is based on linguistic rules, we can easily integrate prior knowledge into the system. The idea of a neuro-fuzzy system is to find the parameters of a fuzzy system by means of learning methods obtained from neural networks.

In this paper, we will use the term neuro-fuzzy systems to refer to all kinds of neuro-fuzzy models regardless of their application area, the main intention of a neurofuzzy approach is to create or improve a fuzzy system by means of neural network methods. Also, we develop a neural fuzzy system learning with linguistic teaching signals. This system is able to process and learn numerical information as well as linguistic information. It can be used as an adaptive fuzzy controller.

This paper is organized as follows; the second section describes the neuro-fuzzy system, including the linguistic information and neuro-fuzzy architecture. The third section is devoted to discuss the system description, including the DC shunt motor. The fourth section is concerned with the design of the proposed controller. Finally, the fifth section presents the conclusions.

\section{NEURO-FUZZY SYSTEMS}

The neural networks and fuzzy systems solve problems by performing function approximation. Neural networks can be used, if we have training data, so that we do not need a mathematical model of the system. But a fuzzy system can be used, if we have knowledge about the solution of the problem in the form of linguistic IF-THEN rules, so that we do not need a formal model of the system and we do not need training data [3-12].

From these considerations, we can easily see that fuzzy systems and neural networks are suitable for modeling expert behavior, if we have knowledge expressed in linguistic rules, we can build a fuzzy system, and if we have data, or can learn from a simulation, then we can use neural networks. The most important reason for combining fuzzy systems with neural networks is their learning capability, such a combination should be able to "learn" linguistic rules and/or membership functions, or to optimize existing ones. Learning in this case means creating a rule base or membership functions based on training data presented as a free learning problem. By a neuro-fuzzy system, we mean that system which involves in some way both fuzzy systems and neural networks, or features of both combined in a single system. There are several 
methodological reasons to use neuro-fuzzy systems in modeling, these reasons are that; fuzzy systems allow modeling of the imprecise but rational behavior of human experts, and neural networks can be trained to model empirical behavior of human experts.

Figure 1 shows different kinds of neuro-fuzzy systems.

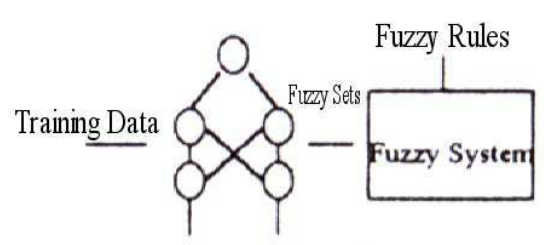

(A) Training Membership Functions

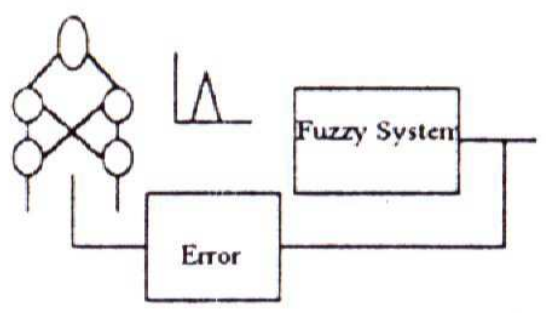

(C) Mernbership Adaptation

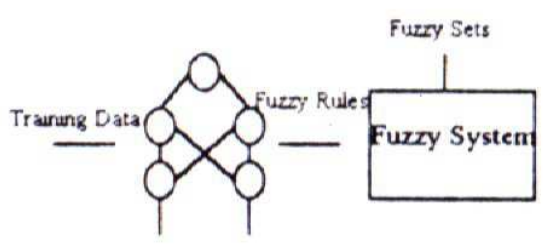

(B) Training Rules

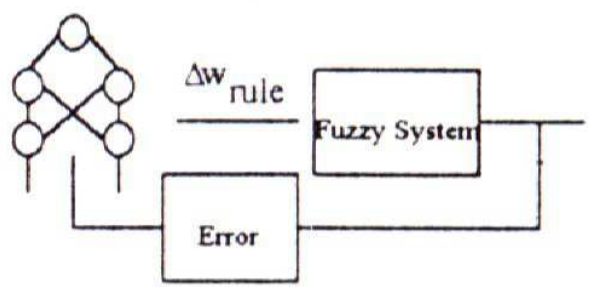

(D) Rule Weights

Fig. 1: Different Neuro-Fuzzy Systems.

\subsection{Linguistic Information}

When constructing information processing systems such as controllers, two kinds of information are available, one is numerical information from measuring instruments and the other is linguistic information from human experts. In this section, we use $\alpha$ level sets of fuzzy numbers to represent linguistic information because of their advantages in both theoretical and practical considerations [3-10]. From theoretical point of view, they effectively study the effects of the fuzziness and the position of a fuzzy number in a universe of discourse. From practical point of view, they provide fast inference computations by using hardware construction in parallel and require less memory capacity for fuzzy numbers defined in universe of discourse with a large number of elements, they easily interface with two-valued logic, and they allow good matching with systems that include fuzzy number operations based on the extension principle.

The $\alpha$-level set of a fuzzy set $\mathrm{P}$, is defined by:

$$
\mathrm{P}_{\alpha}=\left[\mathrm{x} / \mu_{\mathrm{p}}(\mathrm{x}) \geq \alpha\right]
$$

Where $0 \leq \alpha \leq 1$. A fuzzy set $\mathrm{P}$ is convex if and only if every $\mathrm{P}$ is convex, that is $\mathrm{P}$ is a closed interval of $\mathrm{R}$. It can be represented by

$$
\mathrm{P}_{\alpha}=\left[\mathrm{P}_{1}^{(\alpha)}, \mathrm{P}_{2}^{(\alpha)}\right]
$$

where 


$$
\begin{aligned}
\mathrm{P} & =\bigcup_{\alpha} \alpha \mathrm{P}_{\alpha} \\
& =\bigcup_{\alpha} \alpha\left[\mathrm{P}_{1}^{(\alpha)}, \mathrm{P}_{2}^{(\alpha)}\right]
\end{aligned}
$$

For a fuzzy number in the form of $\alpha$-level set, it can be expressed according to the center of area as:

$$
\mathrm{z}=\mathrm{z}_{0}=\frac{\sum_{\alpha} \alpha\left(\mathrm{z}_{1}^{(\alpha)}+\mathrm{z}_{2}^{(\alpha)}\right)}{2 \sum_{\alpha} \alpha}
$$

\subsection{Neuro-Fuzzy Architecture}

In this section, we construct an architecture of a neural-fuzzy system that can process fuzzy and crisp information [3-9]. Figure 2 shows the neural fuzzy system structure with five-layers. This five-layered connectionist structure performs fuzzy inference effectively.

In Layer 1, each node in this layer directly transmits an input fuzzy number $\mathrm{x}_{\mathrm{i}}$ to the next layer. No computation is done in this layer, that is:

$$
\begin{aligned}
\mathrm{O}_{\mathrm{i}}^{1} & =\bigcup_{\mathrm{a}} \alpha\left(\mathrm{o}_{\mathrm{i} 1}^{1(\alpha)}, \mathrm{o}_{\mathrm{i} 2}^{1(\alpha)}\right)=\mathrm{x}_{\mathrm{i}} \\
& =\bigcup_{\mathrm{a}} \alpha\left(\mathrm{x}_{\mathrm{i} 1}^{1(\alpha)}, \mathrm{x}_{2}^{1(\alpha)}\right)
\end{aligned}
$$

In layer 2, "matching", each node in this layer has exactly one input from some input linguistic nodes, and feeds its output to a rule node. For each layer, the input is a fuzzy number and the output is a numerical number. The weight in this layer is a fuzzy number $w, x_{i j}$, the index $i, j$ means the $\mathrm{j}^{\text {th }}$ term of the $i^{\text {th }}$ input linguistic variable $x_{i}$.

The transfer function of each layer-2 node

$$
\begin{aligned}
& \mathrm{f}_{\mathrm{ij}}^{2}=\frac{1}{2} \sum\left[\left(\mathrm{w} \cdot \mathrm{x}_{\mathrm{ij} 1}^{(\alpha)}-\mathrm{u}_{\mathrm{i} 1}^{2(\alpha)}\right)^{2}+\left(\mathrm{w} \cdot \mathrm{x}_{\mathrm{ij} 2}^{(\alpha)}-\mathrm{u}_{\mathrm{i} 2}^{2(\alpha)}\right)^{2}\right] \\
& \text { and } \\
& \mathrm{a}_{\mathrm{ij}}^{2}=\mathrm{a}\left(\mathrm{f}_{\mathrm{ij}}^{2}\right) \\
& \quad=\mathrm{e}^{-\left(\mathrm{f}_{\mathrm{ij}}^{2}\right) / 2 \sigma^{2}}
\end{aligned}
$$

Where $\sigma$ is the variance of the activation function a(.). It is a constant, the activation function of $\mathrm{f}_{\mathrm{ij}}^{2} \in[0, \infty]$, and a $(0)$ is equal 1 .

In layer 3, "Min", the input and output of a node in this layer are both numerical. The links in this layer perform precondition matching of fuzzy logic rules. Hence, the rule nodes should perform fuzzy AND operation. The most commonly used fuzzy AND operations are intersection and algebraic product $[3,7,9,10]$. 


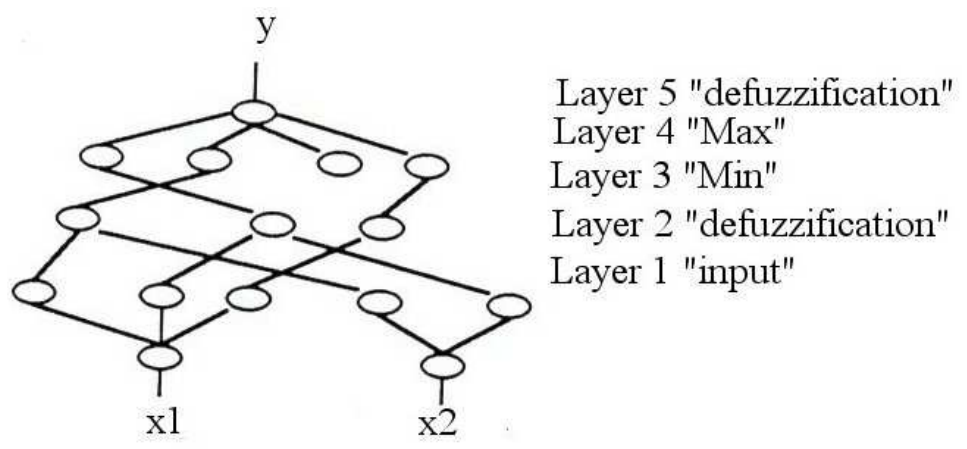

Fig. 2: The Five-Layer Architecture.

If intersection is used, we have

$$
\mathrm{o}_{1}^{3}=\min \left(\mathrm{u}_{1}^{3}, \mathrm{u}_{2}^{3}, \ldots, \mathrm{u}_{\mathrm{k}}^{3}\right)
$$

There is no weight to be adjusted in this layer.

In layer 4, "Max", the nodes in this layer should perform fuzzy OR operation to integrate the fired rules which have the same consequent. The most commonly used fuzzy OR operations are union. If the union operation is used, we have

$$
\mathrm{o}_{\mathrm{i}}^{4}=\max \left(\mathrm{u}_{1}^{4}, \mathrm{u}_{2}^{4}, \ldots, \mathrm{u}_{\mathrm{k}}^{4}\right)
$$

The input and output of each layer-4 node are both numerical values.

In layer 5, "Merging/Defuzzification", in this layer, each node has a fuzzy weight w. $Y_{i}$, there are two kinds of operation in this layer.

The following formula is executed to perform a merging action.

$$
\mathrm{O}_{5}=\bigcup_{\alpha} \alpha\left(\mathrm{o}_{1}^{5(\alpha)}, \mathrm{o}_{2}^{5(\alpha)}\right)=\mathrm{Y}=\frac{\sum_{\mathrm{i}} \mathrm{u}_{\mathrm{i}}^{5} \cdot \mathrm{w} \cdot \mathrm{y}_{\mathrm{i}}}{\sum_{\mathrm{i}} \mathrm{u}_{\mathrm{i}}^{5} .}
$$

namely

$$
\begin{gathered}
\mathrm{Y}=\bigcup_{\alpha} \alpha\left(\mathrm{y}_{1}^{(\alpha)}, \mathrm{y}_{2}^{(\alpha)}\right) \\
\mathrm{wy}_{\mathrm{i}}=\bigcup_{\alpha} \alpha\left(\mathrm{wy}_{\mathrm{i} 1}^{(\alpha)}, \mathrm{wy}_{\mathrm{i} 2}^{(\alpha)}\right) \\
\mathrm{y}_{\mathrm{i}}^{(\alpha)}=\frac{\sum_{\mathrm{i}} \mathrm{u}_{\mathrm{i}}^{5} \cdot \mathrm{wy}_{\mathrm{i} 1}^{(\alpha)}}{\sum_{\mathrm{i}} \mathrm{u}_{\mathrm{i}}^{5} .}
\end{gathered}
$$

where

$$
\mathrm{y}_{2}^{(\alpha)}=\frac{\sum_{\mathrm{i}} \mathrm{u}_{\mathrm{i}}^{5} \cdot \mathrm{wy}_{\mathrm{i} 2}^{(\alpha)}}{\sum_{\mathrm{i}} \mathrm{u}_{\mathrm{i}}^{5}}
$$


If the output of the neural fuzzy system is required to be a numerical value, the output node executes the defuzzification action. The defuzzification method is

$$
\begin{aligned}
\mathrm{f}_{\mathrm{i}}= & \text { defuzzifier (w.yi) } \\
= & \frac{\sum_{\alpha} \alpha\left(w \cdot \mathrm{y}_{\mathrm{i} 1}^{(\alpha)}+\mathrm{w} \cdot \mathrm{y}_{\mathrm{i} 2}^{(\alpha)}\right.}{2 \sum_{\alpha} \alpha .} \\
\mathrm{y} & =\mathrm{O}^{5}=\frac{\sum_{\mathrm{i}} \mathrm{u}_{\mathrm{i}}^{5} \cdot \sigma_{\mathrm{i}} \mathrm{f}_{\mathrm{i}}}{\sum_{\mathrm{i}} \mathrm{u}_{\mathrm{i}}^{5} \cdot \sigma_{\mathrm{i}}}
\end{aligned}
$$

where

$$
\sigma_{\mathrm{i}}=\sum_{\alpha}\left(\mathrm{w} \cdot \mathrm{y}_{\mathrm{i} 2}^{(\alpha)}-\mathrm{w} \cdot \mathrm{y}_{\mathrm{i} 1}^{\alpha}\right)
$$

The five-layered neural network with fuzzy output as fuzzy connectionist architecture with linguistic output "FCLO", and that with numerical output as fuzzy connectionist architecture with numerical output "FCNO" are possible fuzzy numbers in the form of $\alpha$-level sets.

\subsection{Neuro-Fuzzy Controller}

In this section, we develop a neural fuzzy system learning with linguisitic teaching signals. This system is able to process and learn numerical information as well as linguistic information. If can be used as an adaptive fuzzy controller. The proposed neuro-fuzzy techniques have confirmed the effectiveness of the human operator in the presence of system nonlinearities.

Figure 3 provides a schematic representation of a neuro-fuzzy model in the form of a neuro-fuzzy controller. The advantage of such an approach is the unified architecture, which makes a combination between the different systems, which is usually capable of on-line and off-line learning. The idea of this approach is to interpret the rule base of a fuzzy system in terms of a neural network. In this model, the error signal can be viewed as an important feature of the learning algorithm.

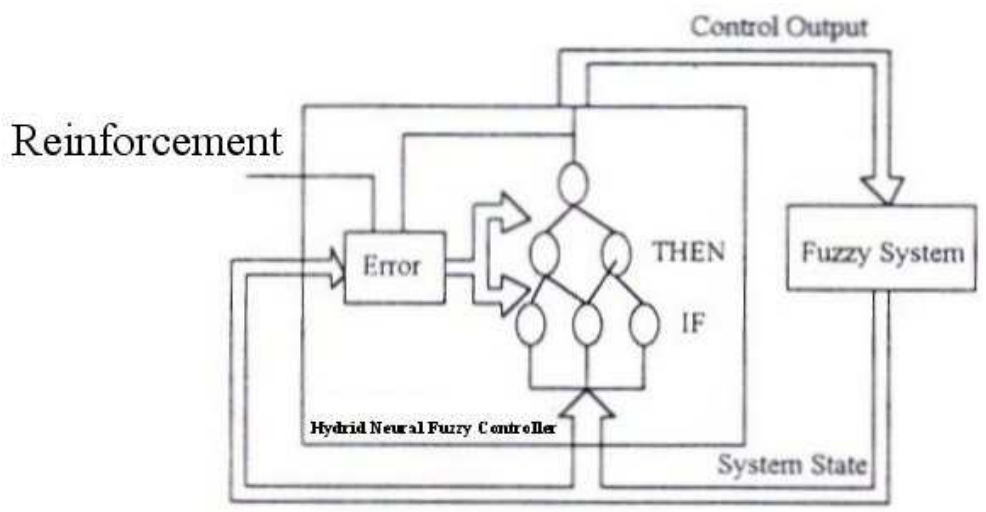

Fig. 3: A Neuro-Fuzzy Controller. 


\section{DC SHUNT MOTOR}

DC electric motors are used as the primary means for robotics manipulators and guided vehicles. Their applications are wide spread ranging from robots to steel and paper mils. This trend is enhanced by continuous developments in the design of electric DC motor drives. All ensure low cost, light weight, and reliable motor drives, which can be easily controlled. There has been significant progress in the area of control systems [13-17].

\subsection{Problem Formulation}

The mathematical model of the DC shunt motor is a nonlinear third order one expressed as follows:

$$
\begin{aligned}
& \mathrm{V}_{\mathrm{T}}=\mathrm{R}_{\mathrm{a}} \mathrm{I}_{\mathrm{a}}+\mathrm{L}_{\mathrm{a}} \frac{\mathrm{dI}_{\mathrm{a}}}{\mathrm{dt}}+\mathrm{K}_{\phi} \omega \mathrm{I}_{\mathrm{f}} \\
& \mathrm{V}_{\mathrm{T}}=\mathrm{R}_{\mathrm{f}} \mathrm{I}_{\mathrm{f}}+\mathrm{L}_{\mathrm{f}} \frac{\mathrm{dI}_{\mathrm{f}}}{\mathrm{dt}} \\
& K_{\phi} I_{f} I_{a}=J \frac{d \omega}{d t}+B \omega+T_{L}
\end{aligned}
$$

Where:

$\mathrm{R}_{\mathrm{a}}, \mathrm{R}_{\mathrm{f}} \quad$ : The armature and field resistances in $\Omega$

$\mathrm{L}_{\mathrm{a}}, \mathrm{L}_{\mathrm{f}}$ : : The armature and field inductances in $\mathrm{H}$

$\mathrm{I}_{\mathrm{a}}, \mathrm{I}_{\mathrm{f}} \quad$ : The armature and field currents in A

$\omega \quad$ : The motor speed in R.P.M

$\mathrm{V}_{\mathrm{T}} \quad$ :The applied motor voltage in $\mathrm{V}$

$\mathrm{J} \quad$ : The motor inertia

B :The viscous friction

$\mathrm{T}_{\mathrm{L}} \quad$ :The load torque

$\varphi \quad$ : The air gap flux

It is worth noting that the term $K_{\phi}$ is a varying gain representing the relation between the field current $I_{\mathrm{f}}$ and the air gap flux. In addition, the bilinearity in Eq. (11) represents nonlinear quantity due to inherent magnetic saturation characteristics. To overcome this bilinearty, given that, saturation exists, a feedback linearization technique had been considered and better performance had been obtained $[15,17,18]$.

This model contains a product of variable type nonlinearities, the nonlinearities are of the polynomial type. Using the state space representation:

Let

$$
\begin{aligned}
& x_{1}(t)=\omega(t) \\
& x_{2}(t)=i_{f}(t) \\
& x_{3}(t)=i_{a}(t)
\end{aligned}
$$

Then

$$
\begin{aligned}
& x_{1}(t)=a_{11} x_{1}(t)+a_{12} x_{2}(t) x_{3}(t)+b_{11} u_{1}(t) \\
& x_{2}(t)=a_{22} x_{2}(t)+b_{22} u_{2}(t) \\
& x_{3}(t)=a_{31} x_{1}(t) x_{2}(t)+a_{33} x_{3}(t)+b_{32} u_{2}(t)
\end{aligned}
$$


Where

$$
\begin{aligned}
& a_{11}=-b / j, a_{12}=k / j, b_{11}=-1 / j \\
& a_{22}=-R_{f} / L_{f}, b_{22}=-1 / L_{f} \\
& a_{31}=-k / L_{a}, a_{33}=R_{a} / L_{a}, b_{32}=-1 / L_{a}
\end{aligned}
$$

In compact form

$$
X(t)=f(x)+B u(t)
$$

Where

$$
\begin{aligned}
\mathrm{x}(.) & =\left[\mathrm{x}_{1}(.), \mathrm{x}_{2}(.), \mathrm{x}_{3}(.)\right] \\
& =\left[\omega(.), \mathrm{i}_{\mathrm{f}}(.), \mathrm{i}_{\mathrm{a}}(.)\right] \\
\mathrm{u}(.) & =\left[\mathrm{u}_{1}(.), \mathrm{u}_{2}(.)\right] \\
& =\left[\mathrm{T}_{\mathrm{L}}(.), \mathrm{V}_{\mathrm{T}}(.)\right]
\end{aligned}
$$

And

$$
\begin{aligned}
& =\mathrm{a}_{11} \mathrm{x}_{1}(\mathrm{t})+\mathrm{x}_{12} \mathrm{x}_{2}(\mathrm{t}) \mathrm{x}_{3}(\mathrm{t}) \\
\mathrm{f}(\mathrm{x}) & =\left[\mathrm{a}_{22}(\mathrm{t}) \mathrm{x}_{2}(\mathrm{t})\right] \\
& =\mathrm{a}_{31} \mathrm{x}_{1}(\mathrm{t}) \mathrm{x}_{2}(\mathrm{t})+\mathrm{a}_{33} \mathrm{x}_{3}(\mathrm{t})
\end{aligned}
$$

\subsection{Fuzzy Logic Controller}

The fuzzy logic controller belongs to a general class of fuzzy logic systems [205$214]$ in which control variables are transformed into fuzzy sets (FUZZIFICATION) and manipulated by a collection of (IF-THEN) fuzzy rules, assembled in what is known as the fuzzy inference engine. These rules are derived from the knowledge of experts with substantial experience in the system.

The basic configuration of a fuzzy logic control system "FLC" is shown in Fig. 4. There are four principle components in a fuzzy logic system: the fuzzifier that maps crisp points in the input space into fuzzy sets in the input space, the fuzzy rule base which comprises fuzzy rules describing how the fuzzy system performs, the fuzzy inference engine which uses the rules in the fuzzy rule base to determine a mapping based on the fuzzy logic operations, and the defuzzifier which maps fuzzy sets in the output space into crisp points in the output space. Within each component, there are many different choices that can be made, and many combinations of these choices result in different fuzzy logic systems [21-27].

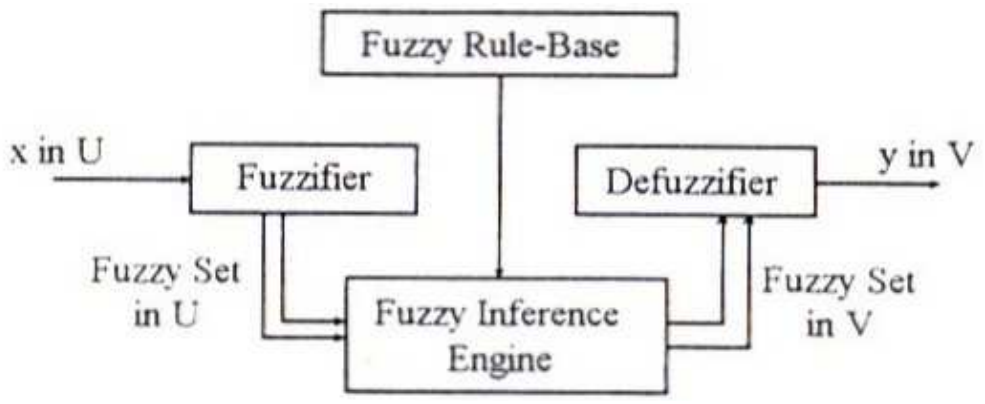

Fig. 4: The Basic Configuration of the Fuzzy Logic System. 
In the following, the data for a $4 \mathrm{~kW}-220 \mathrm{~V}-1450$ r.p.m. DC shunt motor are given [19-21].

$$
\begin{array}{ll}
\mathrm{R}_{\mathrm{a}}=1 \Omega & \mathrm{L}_{\mathrm{a}}=5 \mathrm{mH} \\
\mathrm{R}_{\mathrm{f}}=338 \Omega & \mathrm{L}_{\mathrm{f}}=5 \mathrm{mH} \\
\mathrm{B}=0.0184 \mathrm{Nm} / \mathrm{rad} / \mathrm{sec} & \\
\mathrm{J}=0.05 \quad \mathrm{~kg} \cdot \mathrm{m}^{2} & \\
\mathrm{~K}=2.2088 \mathrm{~V} / \mathrm{amp} \cdot \mathrm{rad} / \mathrm{sec} &
\end{array}
$$

Hardware: 386-AT computer

Software: The program is written using

QB - language

\section{COMPUTER SIMULATION}

Three different tests were performed to study the effects of different parameters on the closed loop system performance. The results indicate the closed loop response of the DC shunt motor for different $\alpha$-cut techniques.

The different tests were performed to study the effects of different $\alpha$-cut techniques on the closed loop system performance. The first test addresses the effect of the $\alpha$-cut techniques. The response is documented in Fig. 5, and shows that the neurofuzzy control becomes much faster. In this mode, the response shows a significant improvement in the system performance when the $\alpha$-cut decreases.

On contrary to that, increasing the number of labels to five labels degrades the neuro-fuzzy controller compared to the case of three labels, in this test, the effect of the labels is addressed and the response is documented in Fig. 6. The response shows that increasing the number of labels results in reaching the steady state much faster with a minor increase in the steady state errors.

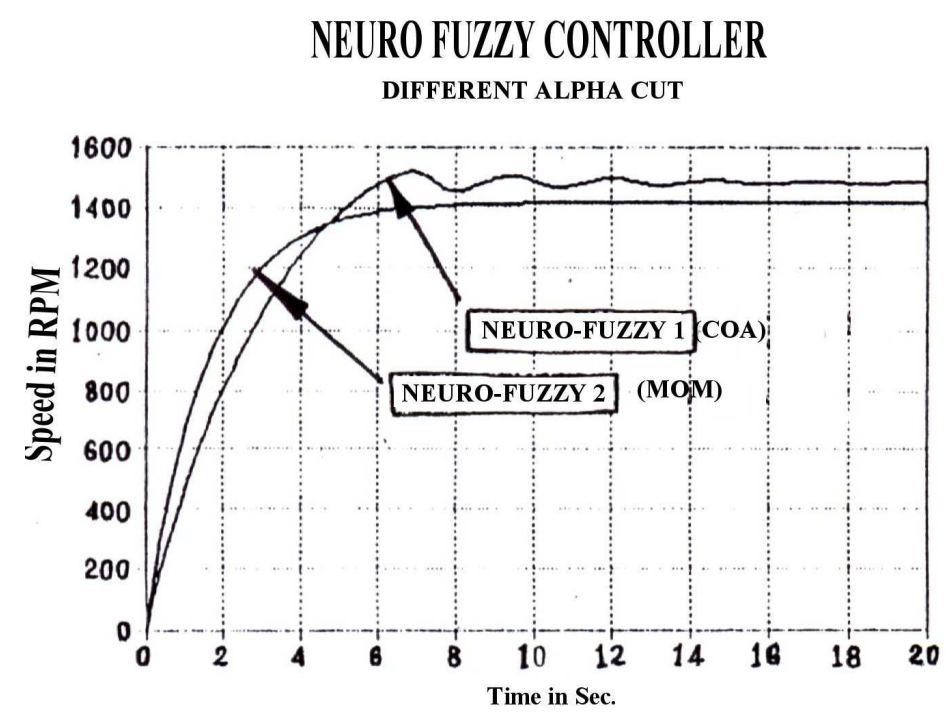

Fig. 5: The Effect of $\alpha$-cut on the Speed Response. 
As we expected, the results in Fig. 7 depict a validation of a neuro-fuzzy controller to control the DC shunt motor, and the results validate that the motor dynamic response is free speed overshoot for different defuzzification techniques. In case of MOM defuzzification technique, the response is faster than in case of COA defuzzification technique [21-27].

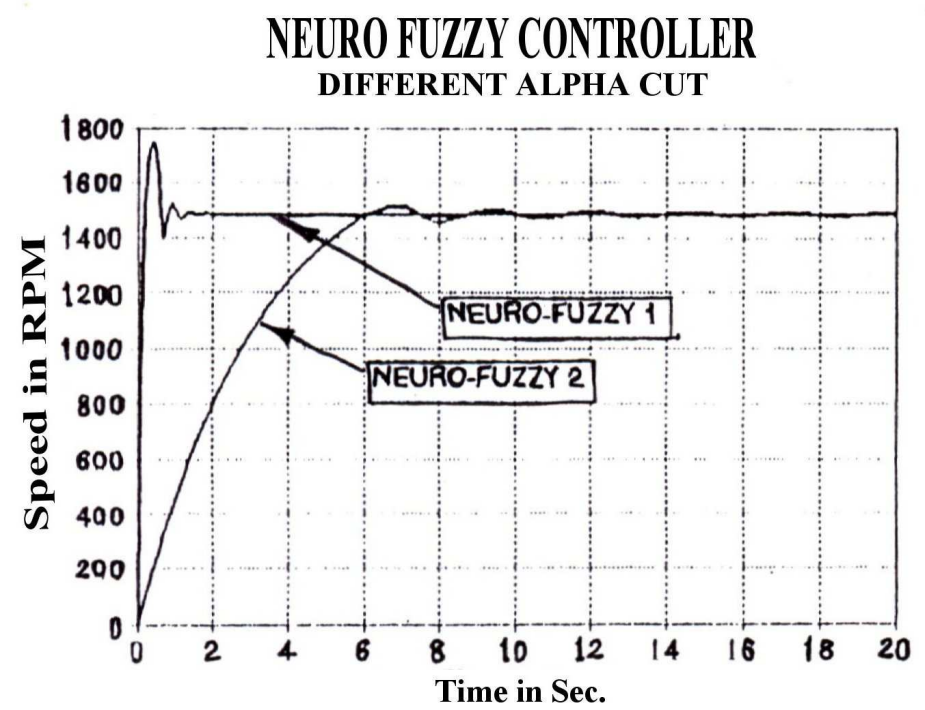

Fig 6: The Speed Response of a DC Shunt Motor for Different Labels.

\section{NELRO FUZZY CONTROLLER DIFFERENT DEFUZZIFICATION}

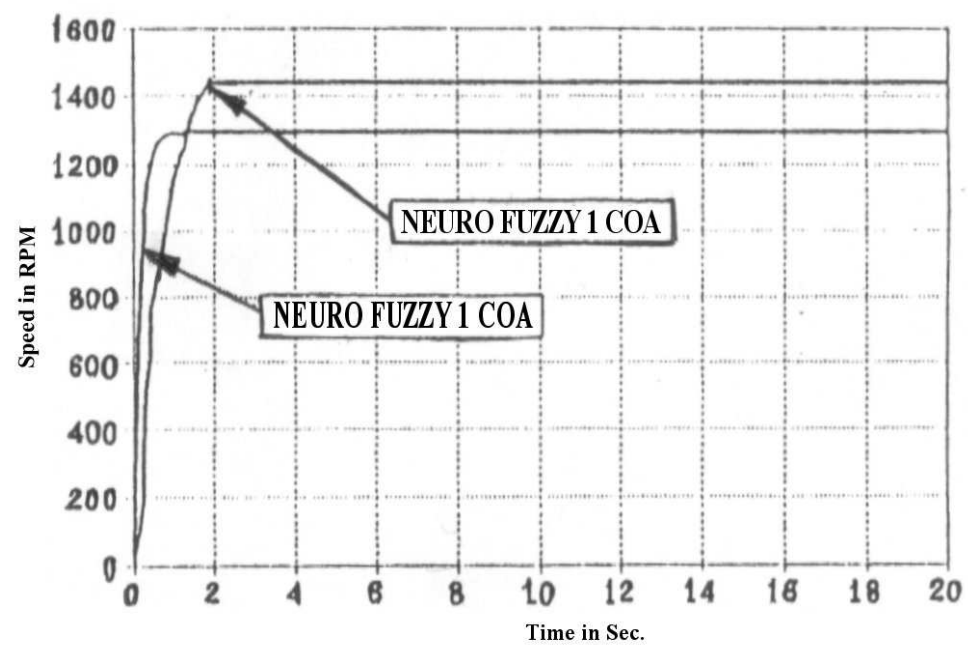

Fig. 7: The Effect of Defuzzification Techniques on the System Response. 


\section{CONCLUSION}

In this paper, we proposed a neural-fuzzy system that processes both numerical and linguistic information. The proposed system has some characteristics and advantages. The inputs and outputs are fuzzy numbers or numerical numbers, the weights of the proposed neural-fuzzy system are fuzzy weights, owing to the representation forms of the $\alpha$-level sets. The fuzzy weights, fuzzy inputs, and fuzzy outputs can be fuzzy numbers of any shape, and except the input-output layers, numerical numbers are propagated through the whole neural-fuzzy system.

The proposed system can be used for a fuzzy expert system. It can be used as an adaptive fuzzy controller, computer simulation satisfactorily verified the performance of the proposed neural-fuzzy system.

The different tests were performed to study the effects of different $\alpha$-cut techniques on the closed loop system performance. The first test addresses the effect of the $\alpha$-cut techniques. On contrary to that, increasing the number of labels to five labels degrades the neuro-fuzzy control compared to the case of three labels. The response shows that increasing the number of labels results in reaching the steady state much faster with a minor increase in the steady state errors, and the results validate that the dynamic response is free speed overshoot for different defuzzification techniques.

As it is expected, the results depict a validation of a neuro-fuzzy control to control the highly complex dynamic system.

\section{REFERENCES}

[1] L. A. Zadeh. “Fuzzy Logic, Neural Networks and Soft Computing”. Fuzzy systems, vol. 57, No. 3, March 1994.

[2] L. A. Zadeh. "Soft Computing and Fuzzy Logic". IEEE Software, Nov. 1994.

[3] C. T. Lin, and C. S. G. Lee. "Neural Fuzzy Systems: A Neuro-Fuzzy Synergism to Intelligent Systems". Prentice Hall Inc., PTR, NJ. 1996.

[4] J. T. Spooner and K. M. Passino. "Stable Adaptive Control Using Fuzy Systems and Neural Networks". IEEE Trans. on Fuzzy Systems, Vol. 4, No. 3, Aug. 1996.

[5] T. Tani, S. Murakoshi, and M. Umano. "A Neuro-Fuzzy Hybrid Control System of Tank Level in Petroleum Plant”. IEEE Trans on Fuzzy Systems, Vol. 4, No. 3. Aug. 1996.

[6] C. T. Lin, and Y. C. Lu. "A Neural Fuzzy System with Linguistic Teaching Signals". IEEE Trans. on Fuzzy Systems. Vol. 3, No. 2, May 1995.

[7] Wei Li. "A Method for Design of a Hybrid Neuro-Fuzzy Control System Based on Behavior Modeling”. IEEE Trans. on Fuzzy Systems. Vol. 5, No. 1, Feb. 1997.

[8] S. J. Huang, and R. J. Lian. "A Hybrid Fuzzy Logic and Neural Network Algorithm for Robot Motion Control'. IEEE Trans. on Fuzzy Systems. Vol. 44, N. 3, June, 1997.

[9] B. Kosko. "Neural Networks and Fuzzy Systems: A Dynamically Systems Approach to Machine Intelligence”. Prentice-Hall, Inc. New Jersey, 1992.

[10] D. Nauck, F. Klawonn, and R. Kruse. "Foundations of Neuro-Fuzzy Systems". John-Wiley \& Sons, 1997. 
[11] R. P. Lippmann. "An Introduction to Computing with Neural Nets". IEEE ASSP Magazine, April 1987.

[12] P. J. W. Melsa. “Neural Networks, Conceptual Overview”. Internal Report, Tellabs Research Center, TRC-89-08, Aug. 1989.

[13] I. Boldea and S. A. Nasar. "Electric Machines Dynamics". Macmillan Publishing Company, New York, 1986.

[14] P. C. Krausem. "Analysis of Electric Machinery“. McGraw-Hill Book Cmpany, New York, 1986.

[15] I. H. Khalifa, and E. A. Sarhan. "A Knowledge-Based Speed Control of Separate Excited DC Motor”. Egyptian Computer Science Journal, Vol. 11, No. $1,1980$.

[16] I. H. Khalifa, and E. A. Sarhan. "Optimal Modeling of a DC Shunt Motor Using Artificial Neural Networks". Proc. of the $18^{\text {th }}$ IFIP TC7 Conference on System Modeling and Optimization, Detroit, MI, 1997.

[17] I. H. Khalifa, and S. A. Ibrahim, "Robust Adaptive Control for High Performance DC Drives" $15^{\text {th }}$ International Congress for Statistics, Ain Shams University, March 1990.

[18] I. H. Khalifa, A. El. Assal and M. H. Saleh, "Feedback Linearization Using Reduced Order Observer for DC Shunt Motors". The $22^{\text {nd }}$ International Conferences for Statistics, Computer Science; Scientific and Social Applications, ICSCSA'97, pp.: 458-462, May 3-19, Cairo, Egypt, 1997.

[19] I. H. Khalifa and A. El-Husban "Feedback Linearization for DC Shunt Motor Control”, Engineering Research Bulletin, ICECS' 95, Vol. 5, pp. 321-331, June 1995.

[20] W. Leonhard “Control of Electrical Drives” Springer-Verlag Berlin, 1990.

[21] I. H. Khalifa, A. El. Assal and M. H. Saleh, "Fuzzy Logic Controller for MultiArea Load Frequency Control of Electric Power Systems", The $6^{\text {th }}$ Conference on Computer Theory and Applications, IEEE, Alex. Chapter, Alexandria, Egypt, September, 1996.

[22] I. H. Khalifa, A. El. Assal and M. H. Saleh. "An Adaptive Fuzzy Control for Dynamically Interconnected Large-Scale System”. The $6^{\text {th }}$ International Middle East Power System, Conference MEPCON'98, Al-Mansoura University, Al-Mansoura, Egypt, 1998.

[23] I. H. Khalifa, A. El-Assal and M. H. Saleh. "A Fuzzy Logic Speed Control of a DC Shunt Motor'. The Fifth International Middle East Power System, Conference MEPCON'97, Alexandria University, Alexandria, Egypt, pp. 76-81, January 4-6, 1997.

[24] I. H. Khalifa, A. El-Assal and M. H. Saleh. "Sensitivity Analysis of Non-Linear System Response Under Different Defuzzification Techniques". The IEEA International Annual Conference of the University of Batna, Algeria, IEEA'97, Batna, Algeria, October 13-15, 1997.

[25] I. H. Khalifa, A. El-Assal and M. H. Saleh. "An Adaptive Fuzzy Controller to Improve System Performance". The $7^{\text {th }}$ Conference on Computer Theory and Applications, IEEE “Alex. Chapter", Alexandria,Egypt, pp. $2: 12-2: 16$, September, 1996. 
[26] E. A. Feilat, K. Al-Tallak, and H. Yamin, "Neural Network Based Technique for Discrimination Between Inrush and Internal Faults in Single Phase Transformers". $5^{\text {th }}$ Jordanian International Electrical \& Electronics Engineering Conference, Amman 13-16 Oct. 2003.

[27] M. Masaadeh \& S. Mansi, "Variable Speed Control of Separately Excited DC Motors Using Fuzzy Logic Control Technique". $5^{\text {th }}$ Jordanian International Electrical \& Electronics Engineering Conference, Amman 13-16 Oct. 2003.

وحدة تحكم عصبية مشوشة للتحكم في محرك تيار مستمر من نوع التوازي

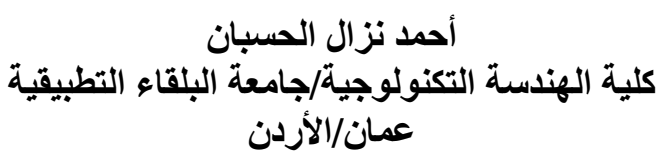

تقدم هذه الورقة منهجية جديدة لتصميم وحدة تحكم باستخدام التقنية العصبية المشوشة بهدف التحكم بالأنظمة اللاخطية ذات البنى والمتغيرات المعروفة. وبسبب اللاخطيات

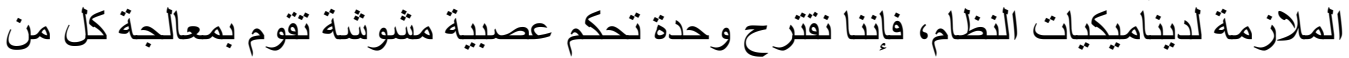

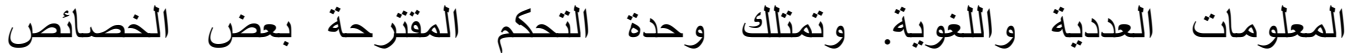

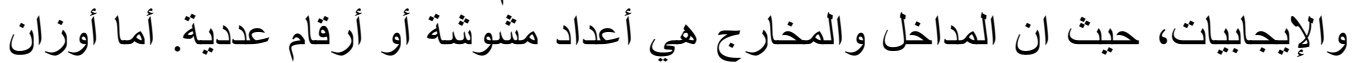

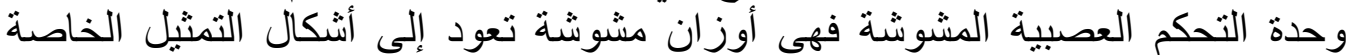
بضبط مستوى ألفا.

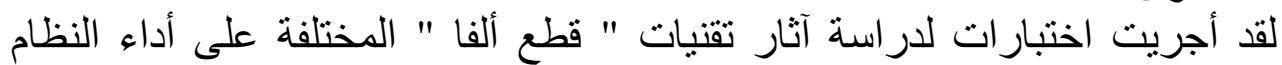

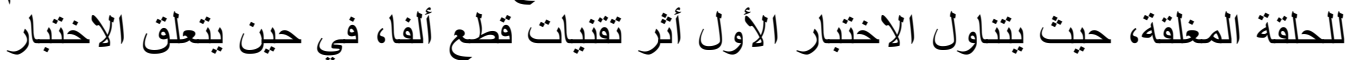

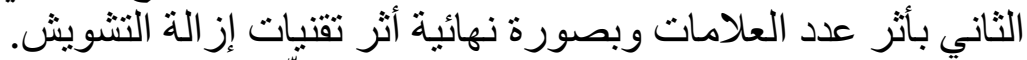

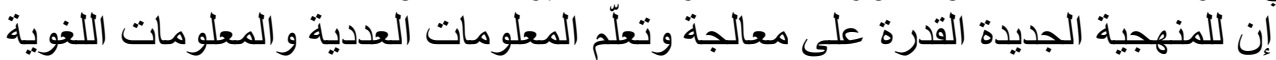

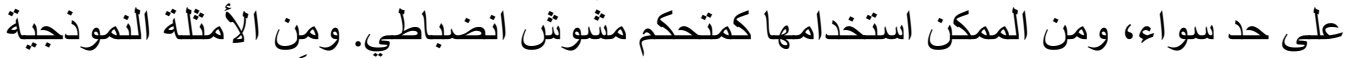

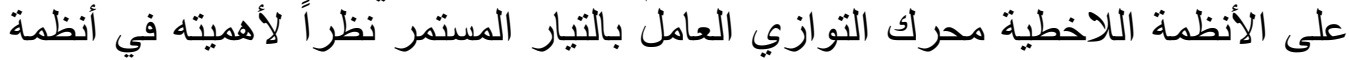
القيادة الكهربائية. كما تم تضمين البحث بعض المض أمثلة المحاكاة الحاسوبية للمساعدة في

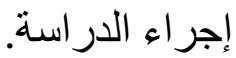
الكلمات الدالة: التحكم العصبي المشوش، اللاخطية، الأوزان المشوشة، مستوى ألفا، الأداء للحلقة المغلقة، محرك تيار مستمر من نوع التهدي التوازي. 